\title{
THE MEASUREMENT OF THE TUBULAR EXCRETORY MASS, EFFECTIVE BLOOD FLOW AND FILTRATION RATE IN THE NORMAL HUMAN KIDNEY
}

\author{
By HOMER W. SMITH, WILLIAM GOLDRING AND HERBERT CHASIS \\ (From the Departments of Physiology and Medicine, New York University College of Medi- \\ cine, and the Third (New York University) Medical Division of Bellevue Hospital, \\ New York City)
}

(Received for publication December 28, 1937)

In exploring the normal and abnormal function of the kidney it is desirable to possess, in addition to knowledge of the filtration rate, knowledge of the total mass of functional renal tissue and the rate of blood flow to this tissue. In theory, both data can be determined by the clearance method, and procedures suitable for these purposes and applicable to man are presented in this paper with the more important physiological considerations upon which these procedures are based. The principles involved in the measurement of the filtration rate and the experimental basis warranting the use of the inulin clearance for this purpose have been reviewed elsewhere $(13,14)$, and the present discussion will be confined to a description of methods for its routine determination and to the presentation of data on the simultaneous inulin and phenol red clearances in 25 normal subjects.

\section{Tubular excretory mass}

Recent investigations have shown that the process of tubular excretion in the lower vertebrates is limited by the circumstance that a given mass of renal tissue can transport from blood to urine only a fixed, maximal quantity of a particular solute per unit time $(12,14)$. It will be shown here that this same limitation applies to the tubular excretion of at least certain substances in man. The measurement of this maximal rate of excretion for any one substance constitutes, therefore, a measurement of what we may call the "tubular excretory mass" of the kidneys.

The measurement of this tubular excretory mass may be approached by a brief discussion of the excretion of phenol red, diodrast and hippuran in man, as illustrated in Figures 1, 2, and 3. These data are taken from observations in which the simultaneous inulin, phenol red, and diodrast or hippuran clearances were determined in nor- mal individuals in whom the plasma concentration of inulin and of one other of these solutes was maintained at a low, constant level, while the concentration of the third solute was raised to a high level. (Details concerning the composition of the infusions and their administration are given in the protocols. Since these clearances are all essentially independent of the rate of urine flow no detailed reference need be made to this factor in the following discussion.)

The data represented by the circles in Figures 1 to 3 will be discussed later in the paper; for the

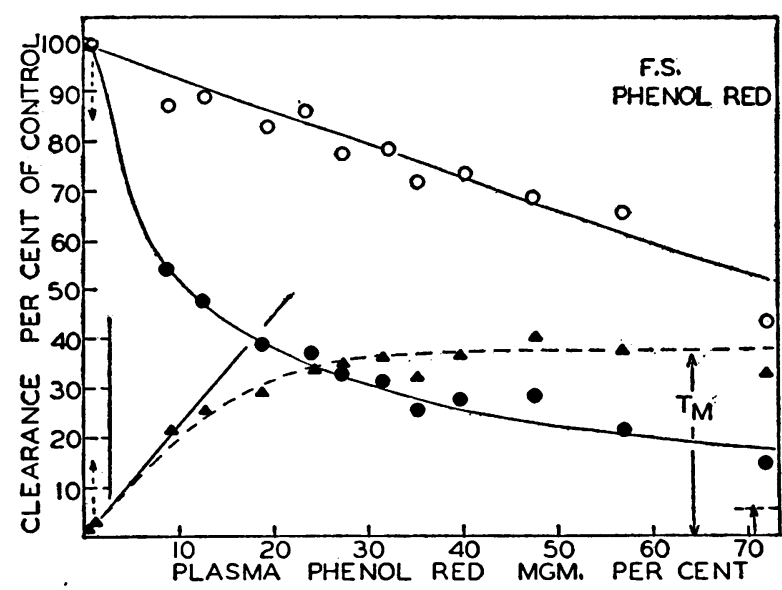

Fig. 1. Effect of Elevated Plasma Concentration of Phenol Red on the Self-clearance (dots) and on the Diodrast Clearance (circles), all Clearances being Expressed in Terms of the Average of Two Control Periods at Low Plasma levels of Phenol RED.

The control clearances were: inulin $=153$, phenol red $=456$, diodrast $=931 \mathrm{cc}$. per minute. Observations were made on a falling plasma phenol red curve after the injection of a single large dose and corrected for delay time. The triangles show the rate of tubular excretion of phenol red (mgm. per minute), the ordinates having the values shown outside the frame. $T_{m}$ is the maximal rate of tubular excretion. The short arrow at the right indicates the minimal (filtration) clearance of phenol red. 


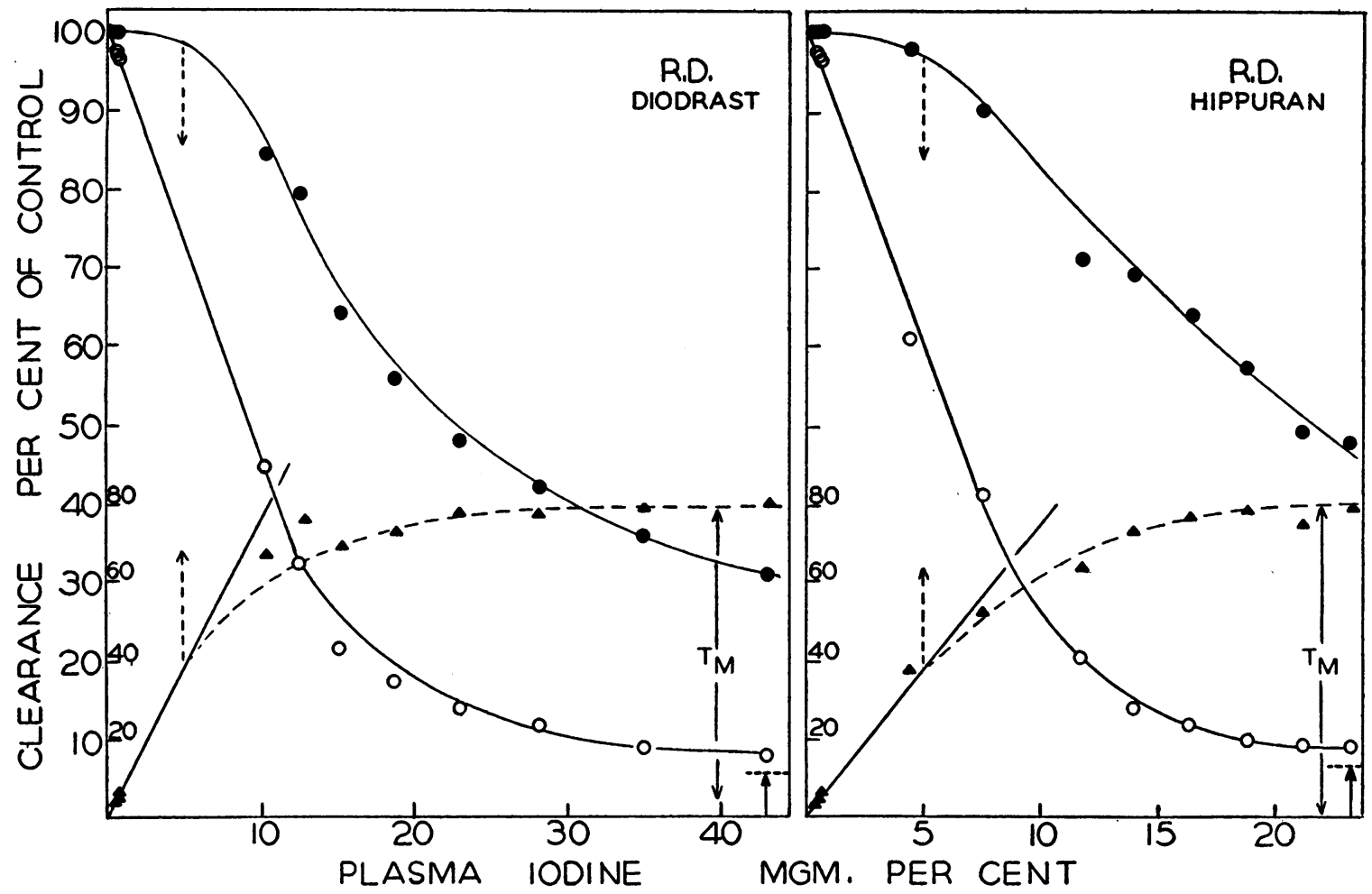

Fig. 2 (left) and Fig. 3 (right). Efrect of Elevated Plasma Concentrations of Diodrast and Hippuran (Both Expressed as Iodine) on the Self-clearance (dots) and on the Phenol Red Clearance (ctrcles), all Clearances being Expressed in Terms of the Average of Three Control Periods at Low Plasma levels of the Iodine Compounds.

The control clearances were (left) inulin $=153$, phenol red $=630$, diodrast $=867$ cc. per minute; (right) : inulin $=161$, phenol red $=545$, hippuran $=803 \mathrm{cc}$. per minute. The observations on diodrast were made on a falling plasma curve after the injection of a large dose of diodrast; those on hippuran were made on a rising plasma curve during the infusion of a strong hippuran solution. Both sets of data corrected for delay time.

The triangles show the rate of tubular excretion of the iodine compounds (mgm. iodine per minute). Below about $5 \mathrm{mgm}$. per cent of diodrast- or hippuran-iodine, the rate of tubular excretion of these substances, $T$, increases in direct proportion to the plasma concentration; in this range, therefore, the clearances are independent of the plasma level. Since the diodrast clearance is essentially complete, it affords a measure of the renal blood flow.

At higher plasma levels the rate of tubular excretion approaches a maximal value, $T_{m}$. This maximal rate is of physiological interest since it is independent of glomerular activity and renal blood flow, and is proportional to the number or mass of normal, active excretory tubules. $T_{m}$ is therefore an index of the tubular excretory mass of the kidneys.

moment the reader is referred to the data represented by the solid dots and triangles. Reference to Figure ' 1 shows that as the plasma concentration of phenol red is raised, the phenol red clearance is depressed. Similarly, the diodrast and hippuran clearances are depressed by the elevation of the respective plasma levels of these solutes (Figures 2 and 3 ). This self-depression of clearance, which was first demonstrated for phenol red in man by Goldring, Clarke, and Smith (8) and for diodrast and hippuran in the dog by Elsom, Bott, and Shiels (4), is owing to the fact that, in man, as in the other vertebrates, the rate of tubular excretion has an upper limit. The rate of tubular excretion, which is shown in the figures by the solid triangles, and which we designate as $T$, is given by the difference between the total excretion per minute, $U V$, and the quantity excreted by filtration: i.e.,

$$
T=U V-P I W F=\left(\frac{X}{I}-W F\right) P I,
$$


where $U$ is the concentration of solute per cc. of urine, $V$ the rate of urine formation in cc. per minute, $P$ the quantity of solute in each cc. of plasma, $I$ the concurrent rate of glomerular filtration as measured by the simultaneous plasma inulin clearance, $X$ the plasma clearance of the solute under investigation, $W$ the fraction of water in the plasma and $F$ the fraction of solute which is free in the plasma and therefore available for filtration. In this calculation, reference is made to the data on the binding of phenol red, hippuran, and diodrast by plasma proteins reported by Smith and Smith (17).

At low concentrations of solute, $T$ increases closely in proportion to plasma concentration; it follows that in this range the clearance has a maximal value and is independent of plasma concentration, as shown by the early horizontal portion of the clearance curve at the left of the vertical dotted arrows. But as the plasma concentration increases, more and more of the solute is delivered to the tubules per unit time and $T$ approaches its maximal value; in consequence of this fact an ever decreasing fraction of the total solute in the blood is removed by tubular activity and the clearance, as calculated on the total output in the urine, falls and approaches the filtration rate as a lower limiting value.

The maximal rate of tubular excretion we designate as $T_{m}$. We may say that the tubules of Subject F. S. are capable of excreting a maximum of $35.8 \mathrm{mgm}$. of phenol red, and that the renal tubules of Subject R. D. are capable of excreting a maximum of $80 \mathrm{mgm}$. of diodrast iodine ( $=161$ mgm. of diodrast) or $80 \mathrm{mgm}$. of hippuran iodine (= $206 \mathrm{mgm}$. of hippuran) per minute when supplied with an abundance of any one of these solutes. These values of $T_{m}$ correspond to 0.10 , 0.32 , and $0.63 \mathrm{mM}$. per minute of phenol red, diodrast, and hippuran, respectively. In three normal subjects hippuran- $T_{m}$ averages 76 , and in five normal subjects diodrast- $T_{m}$ averages 58 mgm. iodine per minute per 1.73 sq. $\mathrm{m}$.

The datum $T_{m}$ is independent of the plasma concentration of solute so long as that concentration is adequate at the existing blood flow to supply a sufficient quantity of solute per unit time to maintain the maximal rate of excretion; and it is likewise entirely independent of the renal blood flow so long as that blood flow is adequate, at the existing plasma concentration, to maintain this maximal rate of excretion. It is also entirely independent of glomerular activity. If one of the kidneys were removed, $T_{m}$ would necessarily be cut in half ; if part of the excretory tissue were destroyed by disease, whether this destruction consisted of local injury of the tubule cells or obliteration of the circulation so that blood no longer reached normal tubules, $T_{m}$ would be reduced in proportion to the extent of this destruction. If, on the other hand, the glomeruli were to be entirely obliterated without impairment of the circulation to the tubules or injury of the tubule cells, $T_{m}$ would remain at its normal value. The maximal rate of tubular excretion can be measured just as well in the aglomerular as in the glomerular kidney, and by appropriate standardization it can be expressed as equivalent grams of normal renal tubular tissue. (Since these substances are probably excreted by the proximal segment only, $T_{m}$ is probably an expression of the development and integrity of proximal tubular tissue.)

It is recognized that tubular activity is manifold and consists not only of the excretion of waste products and foreign substances (creatinine, phenol red, diodrast, etc.), but includes chemical transformations (formation of ammonia, hippuric acid, etc.) and reabsorptive processes (water, glucose, chloride, etc.) ; but it may be assumed that if the integrity of a particular tubule cell is so impaired that it can no longer carry on its normal excretory operations, other operations carried on by that cell will also be impaired. This question is subject to experimental investigation since it should be possible to determine whether the capacity to excrete these various substances is impaired differentially during the course of disease, or whether the excretory capacity is impaired pari passu with other physiological functions, such as the capacity to reabsorb water, glucose, or other substances. Until such differentiation is made we may proceed under the explicitly stated premise that all tubular functions, especially those related to tubular excretion, will vary in a closely parallel manner. In this view we speak of $T_{m}$, the "tubular excretory mass" measured by any suitable substance, as an index of the residual quantity of functional, tubular tissue. 


\section{Effective renal blood flow}

It is, in part, in consequence of the fact that the maximal excretory capacity of the tubules differs for different substances that the clearances of these substances, as determined at low plasma levels, may also be different. All other factors being equal, one might suppose that the greater the excretory capacity of the tubules for a given solute the more efficiently will that solute be removed from the blood as it passes through the kidneys. It is conceivable that for a particular solute, $X$, the excretory capacity of the tubules might be so highly developed that all the $X$ contained in the renal arterial blood would be removed by the combined activity of the glomeruli and the tubules in one circulation through the kidney. If $X$ were neither synthesized nor destroyed by the kidney, and if it were concurrently transferred to the urine, then the clearance of $X$ must in theory be equal to the renal blood flow. In short, the renal blood flow constitutes the highest possible figure which the clearance of any substance not synthesized by the renal parenchyma can have. It cannot be supposed that all the blood entering the renal artery is distributed to excretory tissue, and insofar as any. fraction of the renal arterial blood fails to reach excretory tissue the clearance of $X$ will be proportionately reduced. It is therefore advisable to designate the renal blood flow as measured by the clearance of $X$, the "effective renal blood flow," implying thereby the blood flow to active excretory tissue.

To utilize the clearance method for measuring the effective renal blood flow the following points must be considered.

$a$. The substance, $X$, should be selected upon the basis of having the highest possible clearance, since the highest clearance must approach most nearly the true blood flow.

$b$. The plasma concentration of $X$ must be kept below the level where the clearance is significantly self-depressed.

c. It must be ascertained whether other solutes in the plasma, and particularly substances which are themselves excreted by the tubules, can interfere with the tubular excretion of $X$.

$d$. It must be shown that $X$ is concurrently transferred to the urine.
(Destruction of $X$ by renal tissue and the excretion or storage of $X$ by any other organ do not in theory enter into the problem. Synthesis by renal tissue is patently excluded in the case of foreign substances such as are examined here.)

The above points will be considered separately.

$a$. The relative magnitude of the phenol red, diodrast and hippuran clearances. In our search for substances with high renal clearances in man we have examined numerous compounds, among which are several sulphonphthalein derivatives, the only one of these approaching phenol red in clearance value being anisole red. ${ }^{1}$ But since the latter does not appear to be superior, we have limited the present examination to phenol red. Among organic iodine compounds we have examined skiodan, iopax, neo-iopax, hippuran, and diodrast. A report will be made elsewhere upon the first three, which have low clearances, and the present discussion will be limited to the last two.

Typical hippuran and diodrast clearances, together with simultaneous phenol red and inulin clearances, are given in Table I. In Table II there are given the average values of a series of observations on normal individuals who were selected by the criteria and examined under the basal conditions described later in this paper.

It is evident that both the hippuran and diodrast clearances approach more nearly a complete clearance than does phenol red. In the absence of analytical methods which distinguish diodrast from hippuran, it is impossible to determine by simultaneous observations which substance has the higher clearance. The average plasma or whole blood clearances, as well as the simultaneous inulin or phenol red clearance ratios, give diodrast a slight advantage, and this substance also has the advantage of being bound to a lesser extent by plasma protein, an important consideration in the calculation of $T_{m}$. It is possible, however, that our figures are slightly elevated by a vasodilator action, though we have been unable to demonstrate this systematically.

1 A preparation may be purchased under this name, but Prof. W. M. Clarke advises us that the name may be misleading since the substance it suggests should not behave as one of the ordinary sulphonphthalein indicators. We find the commercial compound to be almost identical in its physiological behavior with phenol red. 
TABLE I

Simultaneous clearances of inulin, phenol red and diodrast or hippuran in normal man



DIODRABT

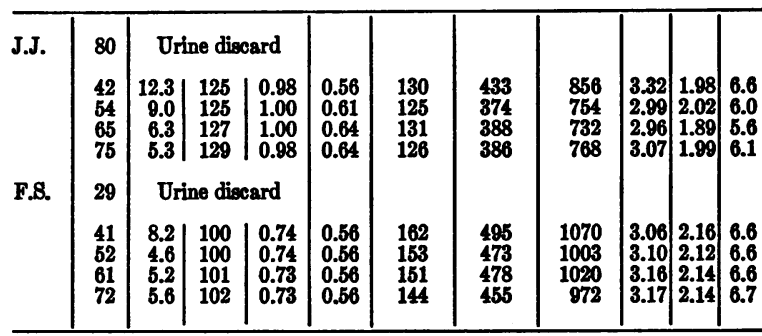

MIPPORAY

\begin{tabular}{|c|c|c|c|c|c|c|c|c|c|c|c|}
\hline \multirow{2}{*}{ J.J. } & 30 & \multicolumn{3}{|c|}{ Urine discard } & \multirow[b]{2}{*}{$\begin{array}{l}0.66 \\
0.73 \\
0.78 \\
0.78\end{array}$} & \multirow[b]{2}{*}{$\begin{array}{l}125 \\
114 \\
120 \\
130\end{array}$} & \multirow[b]{2}{*}{$\begin{array}{l}440 \\
404 \\
417 \\
464\end{array}$} & \multirow[b]{2}{*}{$\begin{array}{l}676 \\
607 \\
602 \\
689\end{array}$} & \multirow[b]{2}{*}{\begin{tabular}{|l|}
3.52 \\
3.53 \\
3.49 \\
3.56
\end{tabular}} & \multirow[b]{2}{*}{$\begin{array}{l}1.54 \\
1.50 \\
1.44 \\
1.49\end{array}$} & \\
\hline & $\begin{array}{l}43 \\
54 \\
65 \\
75\end{array}$ & $\begin{array}{l}11.0 \\
10.0 \\
10.1 \\
10.2\end{array}$ & $\begin{array}{l}118 \\
122 \\
125 \\
126\end{array}$ & $\begin{array}{l}1.00 \\
1.01 \\
1.01 \\
0.90\end{array}$ & & & & & & & \\
\hline \multirow[t]{2}{*}{ A.M. } & 97 & \multicolumn{3}{|c|}{ Urine discard } & & & & & & & \\
\hline & $\begin{array}{l}112 \\
127 \\
143 \\
159 \\
175\end{array}$ & $\begin{array}{l}3.7 \\
3.9 \\
3.4 \\
2.9 \\
3.5\end{array}$ & $\begin{array}{l}133 \\
133 \\
133 \\
127 \\
123\end{array}$ & $\begin{array}{l}0.88 \\
0.95 \\
0.92 \\
0.88 \\
0.84\end{array}$ & $\begin{array}{l}1.08 \\
1.10 \\
1.14 \\
1.10 \\
1.10\end{array}$ & $\begin{array}{l}112 \\
111 \\
108 \\
112 \\
122\end{array}$ & $\begin{array}{l}324 \\
329 \\
324 \\
320 \\
329\end{array}$ & $\begin{array}{l}533 \\
538 \\
491 \\
540 \\
586\end{array}$ & $\begin{array}{l}2.89 \\
2.97 \\
3.00 \\
2.85 \\
2.86\end{array}$ & $\begin{array}{l}1.64 \\
1.64 \\
1.52 \\
1.69 \\
1.78\end{array}$ & \\
\hline
\end{tabular}

* This column gives the elapsed time from the beginning of the intravenous infusion. For details see Methods.

Landis, Elsom, Bott, and Shiels (10) state that neoskiodan penetrates washed human erythrocytes slowly. We find that hippuran and diodrast added to human and dog blood can be recovered from the plasma to the extent of 95 to 97 per cent within the first 30 minutes, as is the case with phenol red (8). This slight deficit we believe to be owing to incomplete centrifugation during the determination of the hematocrit, and we conclude that human red blood cells are for all practical purposes impermeable to these compounds. In view of this fact it follows that all the phenol red, hippuran, or diodrast excreted by the kidneys is carried to these organs by the plasma, and it is only necessary to divide the plasma clearance by the per cent of plasma in whole blood to obtain the corresponding whole blood clearance.

The question of how closely the diodrast clear-
TABLE II

Simultaneous clearances of inulin, phenol red and diodrast or hippuran in normal men *

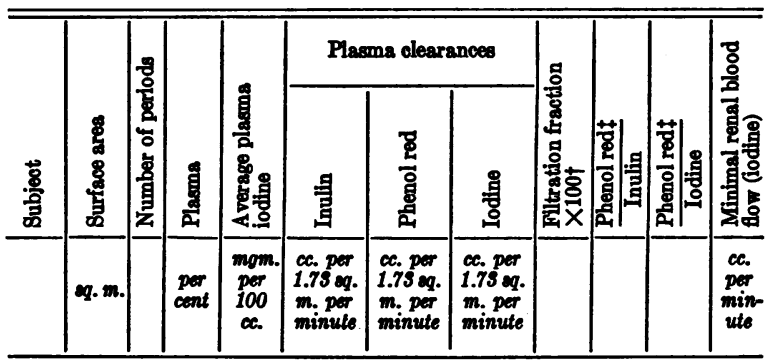

DTODRART

\begin{tabular}{l|l|l|l|l|l|l|l|l|l|l|l}
\hline A.M. & 1.69 & 7 & 0.60 & 0.70 & 122 & & 664 & 18.4 & & & 1107 \\
J.J. & 1.73 & 4 & 0.63 & 0.60 & 128 & 395 & 778 & 16.5 & 3.17 & 0.518 & 1325 \\
H.C. & 1.70 & 4 & 0.61 & 0.75 & 122 & 375 & 718 & 17.0 & 3.20 & 0.522 & 1177 \\
R.D. & 1.80 & 4 & 0.62 & 0.59 & 144 & 498 & 784 & 18.4 & 3.56 & 0.635 & 1265 \\
R.D. & 1.80 & 4 & 0.65 & 0.62 & 137 & 571 & 791 & 17.3 & 4.17 & 0.728 & 1216 \\
F.8. & 1.84 & 4 & 0.55 & 0.56 & 144 & 447 & 956 & 15.1 & 3.20 & 0.468 & 1738 \\
F.8. & 1.84 & 2 & 0.54 & 0.87 & 144 & 429 & 876 & 16.4 & 3.14 & 0.490 & 1622 \\
V.C. & 1.82 & 3 & 0.61 & 0.65 & 156 & 543 & 993 & 15.7 & 3.48 & 0.547 & 1623 \\
\hline & \multicolumn{2}{|c|}{ A verage } & 137 & 463 & 820 & 16.7 & 3.38 & 0.564 & 1384 \\
\hline
\end{tabular}

MIPPURAN

\begin{tabular}{l|c|c|c|c|c|c|c|c|c|c|c}
\hline A.M. & 1.69 & 5 & 0.54 & 1.0 & 120 & 333 & 550 & 21.8 & 2.93 & 0.605 & 1018 \\
J.J. & 1.73 & 4 & 0.63 & 0.75 & 122 & 431 & 644 & 19.0 & 3.68 & 0.670 & 1022 \\
H.C. & 1.70 & 6 & 0.61 & 0.60 & 109 & 394 & 666 & 16.4 & 3.72 & 0.572 & 1092 \\
R.D. & 1.80 & 4 & 0.61 & 0.90 & 132 & 438 & 770 & 17.1 & 3.32 & 0.569 & 1092 \\
R.D. & 1.80 & 3 & 0.66 & 0.75 & 155 & 524 & 803 & 19.3 & 3.38 & 0.652 & 1216 \\
S.H. & 1.74 & 3 & 0.58 & 0.57 & 108 & 353 & 524 & 20.6 & 3.27 & 0.674 & 904 \\
E.T. & 1.89 & 6 & 0.52 & 0.75 & 120 & 324 & 680 & 17.6 & 2.81 & 0.477 & 1307 \\
F.T. & 1.89 & 4 & 0.56 & 2.0 & 115 & 314 & 684 & 16.8 & 3.07 & 0.458 & 1222 \\
\hline & \multicolumn{2}{|c|}{ Average } & 123 & 388 & 665 & 18.5 & 3.16 & 0.584 & 1109 \\
\hline
\end{tabular}

* All observations with constant plasma levels, as in Table I.

$\dagger$ Assuming that the diodrast and hippuran clearances are complete.

$\ddagger$ Corrected for depression of phenol red clearance according to Figure 4.

ance approaches a complete clearance can be answered only by determining what percentage of diodrast is removed from the renal blood, a measurement that requires the simultaneous analysis of blood from the renal vein and the systemic circulation. Observations of this nature have been made on subjects with presumably normal kidneys and will be reported elsewhere (16). For all practical purposes it appears that the diodrast clearance approaches closely enough a complete clearance to be considered identical with the renal plasma flow.

b. Relation of plasma concentration to selfclearance. The phenol red clearance begins to be significantly depressed when the plasma concentration of phenol red is elevated above $1.0 \mathrm{mgm}$. per cent (8) and, except in the observations in Figure 1 where the concentration was raised to a 
high level, our clearances have all been determined within the range of 0.7 to $1.0 \mathrm{mgm}$. per cent.

Numerous observations of a similar nature to those shown in Figures 2 and 3, and which we omit from this record for the sake of brevity, indicate that the diodrast and hippuran clearances are not appreciably depressed at plasma concentrations below $5 \mathrm{mgm}$. per cent of iodine. The lowest concentration at which great accuracy for the analytical method can be claimed, using $5 \mathrm{cc}$. of plasma, is $0.5 \mathrm{mgm}$. per cent of iodine; hence there is ample latitude in the plasma concentration at which the clearances of these substances can be examined.

c. Simultaneous excretion of phenol red and iodine compounds. When the plasma level of phenol red is elevated, the simultaneous diodrast clearance is depressed, even though the concentration of diodrast in the plasma is maintained below the level where self-depression begins. (See circles in Figure 1, where the diodrast clearance was followed at elevated plasma levels of phenol red.) Similarly, elevation of the plasma level of diodrast or hippuran depresses the simultaneous phenol red clearance, as shown by the circles in Figures 2 and 3. Diodrast and hippuran have a powerful effect in depressing the phenol red clearance, whereas phenol red has only a moderate effect in depressing the diodrast clearance. (The action of phenol red on the hippuran clearance has not been examined.) Essentially the same depression in the phenol red clearance is obtained when the concentration of diodrast or hippuran is allowed to fall from high levels as when it is rising from low levels. The depression of the phenol red clearance by diodrast is not a transient one; when the concentration of diodrast is maintained at a high and constant level the phenol red clearance is depressed to a low level, which is maintained steadily for one to two hours. The observations illustrated in Figures 2 and 3 have been repeated a number of times, but it would seem unnecessary for our present purposes to amplify the two examples given. An approximately equal degree of depression of the phenol red/inulin clearance ratio at the same plasma concentrations of the iodine compounds is observed in all normal subjects.

We interpret the above facts as showing that these three substances are in some measure ex- creted by a common tubular mechanism, that they enter into quantitative competition for this mechanism, and that diodrast and hippuran have a relatively great, and phenol red a relatively small, affinity for this mechanism. No other substances are known which specifically affect these clearances, and it is probable that there is no substance normally present in plasma in concentrations sufficient to have an appreciable effect of this nature.

Diodrast and hippuran displace phenol red from its combination with plasma protein and thus increase the free and filtrable fraction (17). When the plasma concentration of either iodine compound is raised to a sufficient extent the phenol red clearance is depressed below the inulin clearance, and nearly down to the level to be expected on the basis of the filtration of free phenol red (Figures 2 and 3 ). This confirms the thesis that it is only the free dye in the plasma that is available for filtration, and that the true filtration clearance of dye is given by the product of the inulin clearance and the fraction of free dye.

For several reasons it is desirable to observe the phenol red and iodine clearances simultaneously in certain experiments pertaining to renal blood flow, as well as in the examination of the diseased kidney. It is therefore necessary to know the critical level at which the iodine compounds first significantly depress the phenol red clearance. Data on this point are given in Figure 4. In these observations the control phenol red and inulin clearances were determined in three periods of about 10 minutes each; a small quantity of iodine compound ( 3 to $10 \mathrm{cc}$. of solution) was then injected into the infusion tubing some distance from the needle, the injection being made slowly ( 1 cc. per minute). ${ }^{2}$

2 Care must be used in this procedure, since the iodine compounds, and diodrast in particular, may produce renal circulatory disturbances which usually are accompanied by a temporary increase in both the iodine and phenol red clearances above the control or anticipated levels. Under these conditions the inulin clearance usually falls, indicating that the increased iodine and phenol red clearance is a result of increased renal blood flow, following dilatation of the efferent glomerular arterioles. This circulatory disturbance makes it difficult to obtain any great precision in either absolute clearances or in inulin clearance ratios when the iodine compounds are given in a concentrated form. Circulatory disturbance is minimal when diodrast is given by slow intravenous infusion of a dilute solution. 


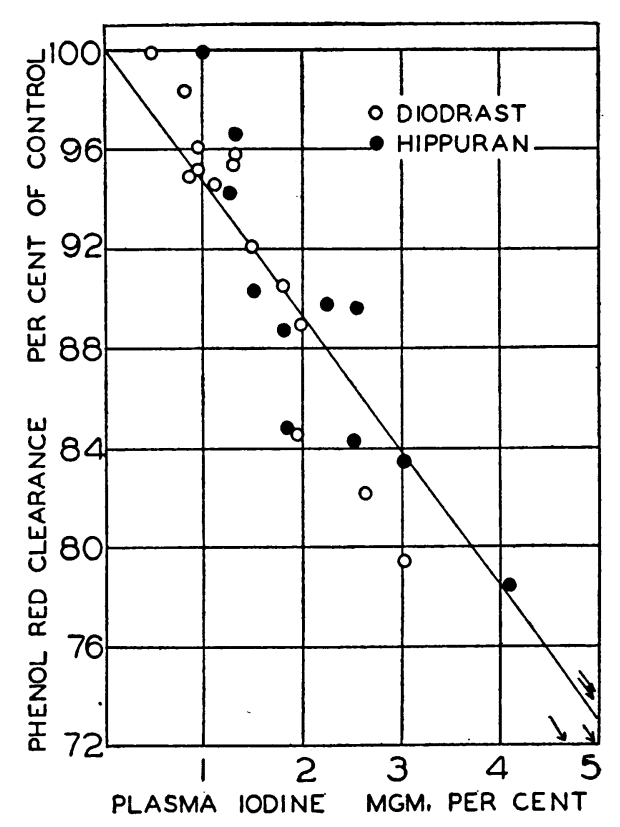

Fig. 4. The Effect of Small Concentrations of DIODRAST OR HipPURAN (EXPRESSEd AS IODINE) UPON the Phenol Red Clearance, as Revealed by Changes in the Absolute Value of this Clearance or in the Phenol Red/Inulin Clearance Ratio.

In drawing the solid curve, consideration is given to the depression caused by higher concentrations of the iodine compounds, as noted in such observations as those recorded in Figures 2, 3 and 5.

From a number of observations we have selected those in which renal circulatory disturbance is apparently minimal, and conclude that at 1.0 mgm. per cent of iodine, neither diodrast nor hippuran depress the phenol red clearance by more than 5 per cent. Conversely, at $1 \mathrm{mgm}$. per cent (see Figure 1) phenol red does not appreciably depress the diodrast clearance, so that simultaneous clearances may be accepted as maximal for both substances in the normal kidney at plasma concentrations below these respective levels. It would appear proper, where these clearances are determined simultaneously, to make a correction on the phenol red clearance such as is indicated by the data of Figure 4.

d. On the possibility of storage of phenol red, etc. in the kidney. It would seem that the most satisfactory method of examining the possibility of storage in the renal parenchyma would be to observe the behavior of the tubules in respect to excretion rate at a time when the plasma concen- tration was rising and had never been higher than at the moment of observation; then, to raise the plasma concentration to higher levels, thus enabling the tubules to take up and store the solute if there is any tendency for them to do so; and then, allowing the plasma level to fall as rapidly as possible, to examine the behavior of the tubules at the reduced plasma level again, at a time when the stored material might be excreted in excess of current delivery by the blood. Goldring, Clarke, and Smith (8) have reported observations of this type on the excretion of phenol red in man which show that this clearance has essentially the same value on both rising and falling curves.

Since the publication of these experiments Elsom, Bott, and Walker (5) have observed in the rabbit that the clearance of hippuran and more particularly of phenol red may considerably exceed the renal blood flow as measured by the thermostromuhr method, and they have concluded that these substances are stored in the kidney. This point is of such fundamental importance, both in the measurement of the tubular excretory mass and the effective renal blood flow, that we have carefully examined the excretion of both hippuran and diodrast in man for evidences of storage by the method outlined above. However, instead of using the hippuran and diodrast clearances themselves as the critical indicator of storage, we have used the depression of the phenol red clearance, the reason for this choice being that the depression of the phenol red clearance is a much more sensitive indicator of the presence of hippuran or diodrast in the plasma, and therefore in the tubule cells, than are the self-clearances; a very small increment in the concentration of the iodine compounds, insufficient to produce appreciable depression of the self-clearance, produces a marked depression of the phenol red clearance. The details of these experiments are given in the protocols, but the general plan may be outlined here. The plasma concentrations of inulin and phenol red were kept constant by suitable intravenous infusions, while (a) hippuran or diodrast was introduced into the circulation in increasing concentration and raised to a high level; the administration of the iodine compound was then stopped and $(b)$ the plasma level was allowed to fall, the rate of fall being extremely rapid since the clearances are large. Clearances obtained in 


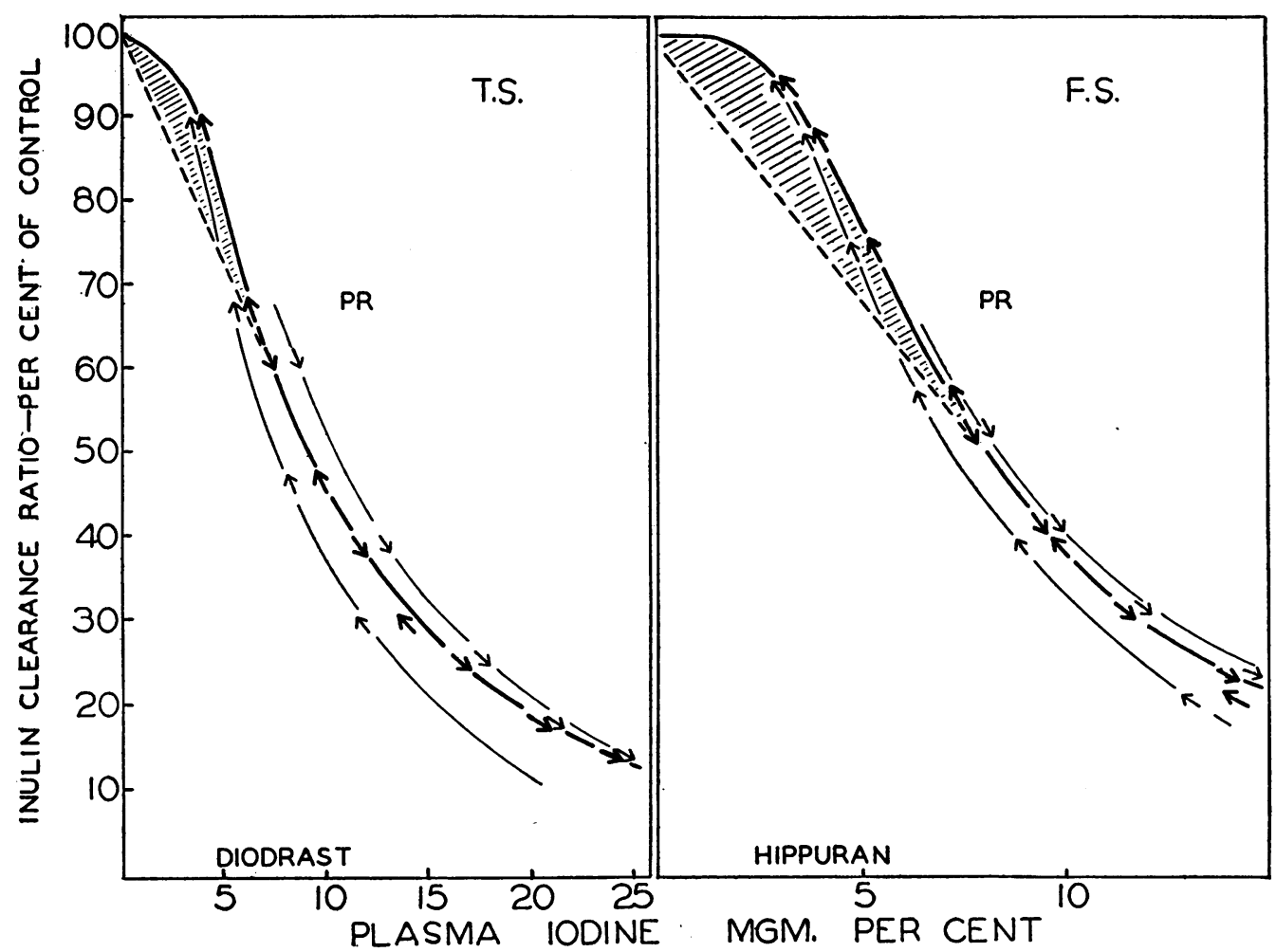

Fig. 5 (left) and Fig. 6 (right). Observations Designed to Examine the Possibility of Storage of Diodrast or Hippuran in the Renal Tubules.

The light arrows indicate the effect of diodrast (left) and hippuran (right) on the phenol $\mathrm{red} /$ inulin clearance ratio when the plasma concentration of the iodine compound is rising, and again when it is falling rapidly. The heavy arrows indicate these clearances corrected for a 150second delay time. The identity of the "rising" and "falling" curves when so corrected indicates that the tubule cells return to the initial equilibrium, as revealed by the urine they elaborate, very quickly after that initial equilibrium has been disturbed by exposure to high concentrations of diodrast or hippuran.

Observations such as those in Figure 4 indicate that the phenol red clearance is depressed in an almost linear manner at the lower concentrations of the iodine compounds; the elevation of the phenol red clearance above the expected level, as shown in the shaded areas, is attributed to the accumulation of phenol red in the interstitial fluid of the kidney. This accumulation is, however, a negligible fraction of the total phenol red which passes through the kidney during the time the phenol red clearance is depressed.

this manner are recorded by the light arrows in Figures 5 and 6 . During $(b)$ the phenol red/ inulin clearance ratio does not retrace the course set during $(a)$, but is displaced, first below and subsequently above, the expected course.

Analyzing this result it must be recognized that a particular sample of urine is formed from blood, not of the average composition possessed by the simultaneous systemic venous blood, ${ }^{8}$ but of the

8 It has been our practice to determine $P$ for clearance calculations by plotting the observed plasma concentrations logarithmically and elapsed time linearly. This average composition existing some seconds before the urine collection period. This interval, which we may designate the "total delay time," is made up of (1) circulation time from antecubital vein to right heart to renal artery to capillary plexus around the tubules; (2) diffusion time from capillary stream through interstitial fluid; (3) penetration into tubule cells, reaction with the excre-

method of interpolation is just as satisfactory as that recommended by Winkler and Parra (21) when, as is the case with these observations, the change in $P$ is exponentially related to time. 
tory mechanism and passage across cells to tubule lumen; (4) dead space time, i.e., the time required for the urine to pass down the tubules, through the pelvis and ureters, to enter the bladder. By the specified conditions of its measurement, the total delay time must include any interval elapsing before the activity of the tubules is readjusted to a previously existing equilibrium after this equilibrium has been seriously disturbed; therefore, "storage" will manifest itself by an increase in interval 3 .

The divergence between the rising and falling curves shown in Figures 5 and 6 constitutes a measure of the total delay time as defined above. In order to determine the magnitude of this total delay time it is only necessary to determine what correction must be applied to the blood curves in our experiments in order to superimpose the two sets of data. Empirically this correction is found in Subject T. S. (diodrast) to be approximately 3 minutes, in Subject F. S. (hippuran), 2 minutes. But a large fraction of this total delay time is owing to the factors enumerated above other than 3 ; these other factors we will designate as the "minimal excretion time," which may be estimated independently by determining the minimal time required for phenol red, when injected intravenously, to appear in the urine, the latter being collected at short intervals by syringe and catheter. This observation was repeated 18 times on 10 subjects, the average minimal excretion time varying from 120 seconds at a urine flow of $20 \mathrm{cc}$. per minute to 200 seconds at a urine flow of $1 \mathrm{cc}$. per minute. At urine flows of 6 to $2 \mathrm{cc}$. per minute, the minimal excretion time averaged 150 seconds. This interval includes all the elements making up the total delay time except the time specifically required for the tubules to arrive at an equilibrium rate of excretion in relation to a given plasma concentration; if delay resulting from storage is appreciable it should be evidenced by a difference between the minimal excretion time and the total delay time. Whether such a difference exists can be tested by correcting the data in the figures by the average minimal excretion time of 150 seconds. When so corrected, as shown by the heavy arrows, the phenol red clearances on the falling plasma iodine curve are identical with those on the rising curve, as indicated by the shaded area, except at the low plasma levels of iodine. This latter phenomenon, we believe, is owing to the fact that during the time when the excretory capacity of the tubules for phenol red is greatly depressed by the presence of large quantities of diodrast and hippuran, free phenol red diffuses out of the capillaries and tends to accumulate in the interstitial fluid of the kidneys in a concentration greater than that present when excretion is proceeding normally; on liberation of the excretory mechanism by removal of the iodine compound, this excess concentration of phenol red is available for excretion and, as calculated on the systemic plasma concentration, the clearance rises to slightly supernormal values. One may speak of this phenomenon as "storage" of phenol red in the kidney as a whole, but not in the renal tubules, and it is negligible in magnitude even under the conditions of these observations. Although the phenol red clearance was depressed below 20 per cent of its normal value, the fraction of phenol red accumulating in the kidney was less than 2 per cent of the total quantity which would have been excreted had the clearance remained at its normal level. In no sense can the phenomenon be interpreted as indicating storage of diodrast or hippuran, which would depress rather than elevate the phenol red clearance.

The above observations show that about 2 to 3 minutes are required for the renal tubules to return to the initial equilibrium, as indicated by the phenol red clearance, after the plasma concentration of hippuran or diodrast has been elevated and allowed to fall again. This interval is not appreciably greater than can be explained by physiological processes $(1,2$, and 4 enumerated above) other than the time required for the reequilibration of the excretory mechanism itself, and consequently it appears that the latter process is extremely rapid. It is concluded that hippuran and diodrast are not stored to a significant extent in the tubules during the process of excretion from low or moderate plasma levels, and in view of Goldring, Clarke, and Smith's (8) observations we may extend this conclusion to phenol red. This conclusion is fortified by the observation that phenol red is transferred from the peritubular fluid to the tubular lumen in a diffuse state, i.e., without accumulation in the vacuoles or granules of the tubule cell (2). 
It would seem appropriate, wherever either glomerular or tubular clearances are determined on a rapidly rising or falling plasma curve, to introduce a correction for delay time by interpolating the blood curve, not to the middle of the urine collection period, but to a point earlier by an appropriate interval. Subsequent mention of the fact that data have been corrected for delay time means that we have deducted 150 seconds from the nominal middle of the urine collection period in this manner.

The exclusion of the possibility of storage enables us to approach the problem of measuring the tubular excretory mass and the effective renal blood flow with greater confidence. In the measurement of the latter, as indeed in all clearance determinations, it is desirable to maintain the plasma concentration of diodrast or phenol
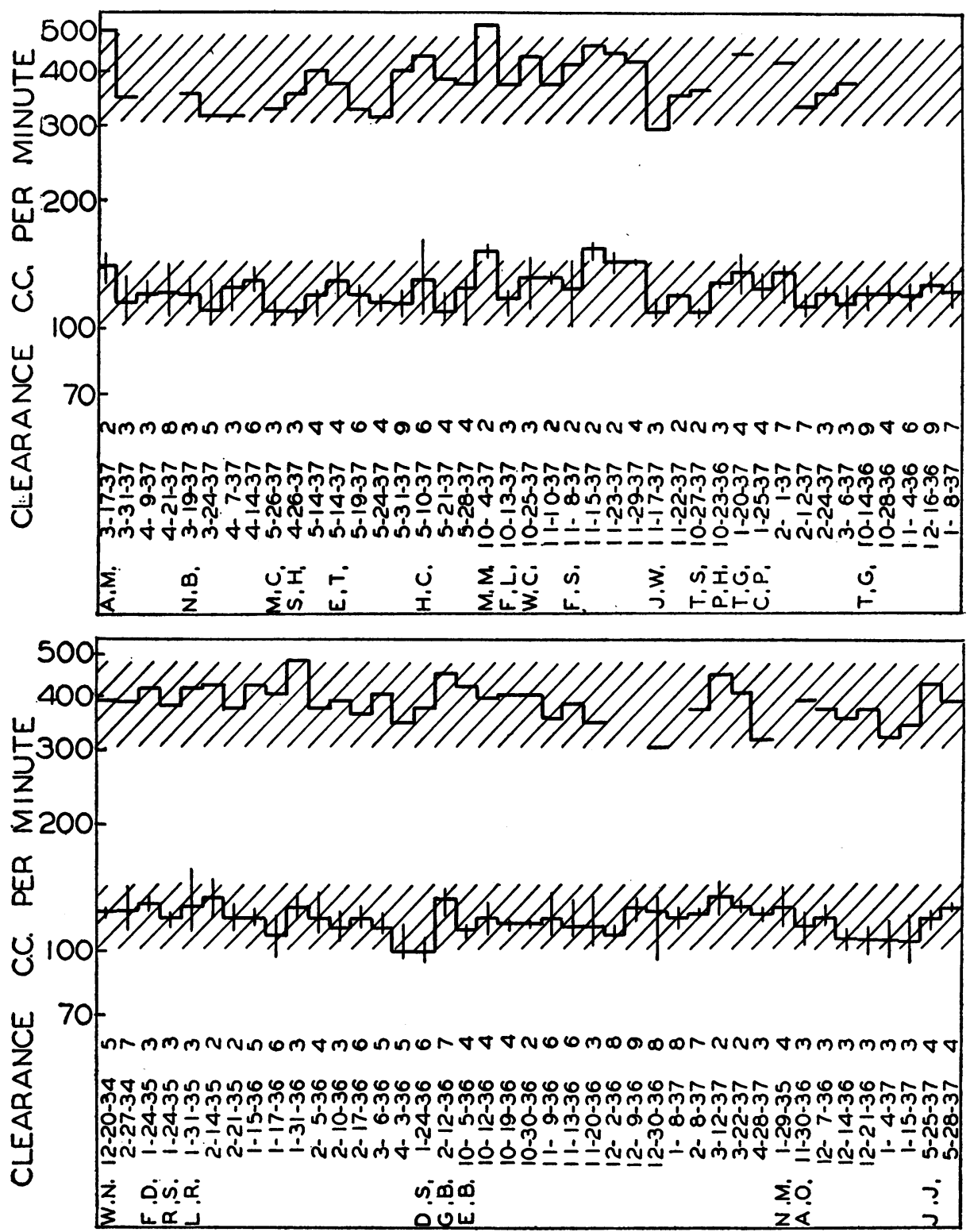

Figs. 7a and $b$. Inulin (Lower) and Phenol Red (Upper) Clearanctes in Normal Subjects, Corrected to 1.73 sQ. M. Surface Area 
red at a constant level by continuous intravenous infusions, so that no correction need be made for delay time. Knowing that the tubule cells reequilibrate themselves within 150 seconds when the plasma concentration is changing, we believe that re-equilibration will occur within the same interval where there are marked changes in the rate of renal blood flow, a circumstance which might be encountered when the action of drugs, etc., is being studied.

\section{Inulin and phenol red clearances in normal man}

A limited series of observations on the inulin and phenol red clearances in normal man have been given by Shannon and Smith (13) and Goldring, Clarke, and Smith (8). Our present data include 25 volunteer, afebrile convalescent patients who showed no immediate evidence or history of circulatory or renal disease. Attention is especially called to the methods of preparing and administering the intravenous infusions, the collection of urine, etc., described under Methods. The concentrations of phenol red and inulin in the plasma were generally maintained at constant levels ranging, respectively, from 0.7 to 1.0 and 100 to $150 \mathrm{mgm}$. per cent. Since these clearances are essentially independent of urine flow this datum has been omitted from the summary. Lack of space prevents the presentation of the data in detail, but the pertinent features are given in Figures $7 a$ and $b$ and in Table III.

The uppermost column of data in the figures gives the number of clearance periods, and the vertical lines indicate the extreme high and low values of the inulin clearance, in each group of observations. The average inulin clearance, crediting each subject once only, is $122.5 \sigma=10.7$. The shaded bands indicate a range of 2 times the standard deviation. Physiologically, it would appear that values falling within $2 \times \sigma$ are normal, between $2 \times \sigma$ and $3 \times \sigma$ suspect, and outside $3 \times \sigma$ definitely abnormal.

Both the inulin and phenol red clearances in various individuals are quite constant, as is demonstrated by the fact that the standard deviations of the average inulin and phenol red clearances are only 8.7 and 11.4 per cent of the respective means. Except in four instances (Subjects D. S., N. B., M. C., and J. W.) the correlation between the simultaneous phenol red and inulin
TABLE III

Summary of urea, inulin, and phenol red clearances in normal man *

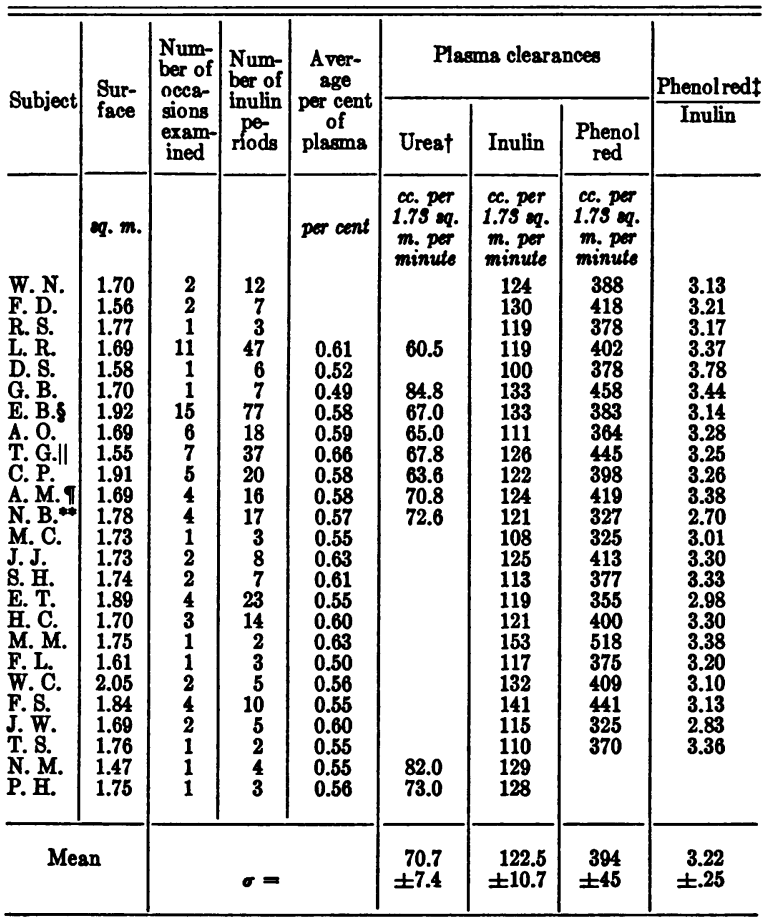

Omitted from average although lacking definite history of renal disease.

\begin{tabular}{l|l|l|l|l|l|l|l|l}
\hline C. B. & 1.74 & 7 & 30 & 0.60 & 55.0 & 96 & 279 & 3.21 \\
J. C. & 1.64 & 5 & 15 & 0.59 & & 93 & 269 & 2.89 \\
\hline
\end{tabular}

* For general methods of determination see Methods.

$\dagger$ Urine flow above $2.0 \mathrm{cc}$. per minute.

$\ddagger$ Based only on periods when both inulin and phenol red clearances were determined simultaneously.

$\$$ Phenol red clearance absent in 17 periods.

II Phenol red clearance absent in 33 periods.

I Phenol red clearance absent in 11 periods.

** Phenol red clearance absent in 6 periods.

clearances is even closer. Subject D. S. was a morphine addict who showed marked withdrawal symptoms on a subsequent examination, and it is possible that there was abnormal vasomotor activity in the kidneys on the single experiment reported here. Nothing known about Subjects J. W., N. B., or M. C. would indicate renal disease, and all four subjects have been included in the calculation of the mean ratio.

Viewing the phenol red clearance as proportional to renal blood flow, the constancy of the relative values of the phenol red and inulin clearances indicates that the filtration fraction in the normal kidney is remarkably uniform. It has been our experience that vasomotor disturbances 
(febrile reactions, drugs, etc.,) are immediately reflected by changes in the phenol red/inulin clearance ratio, in general the inulin clearance tending to fall, the phenol red clearance to rise, a divergence which can be explained by the supposition that the normal glomerular pressure is maintained by tonic constriction of the efferent glomerular arteriole. Dilatation of this vessel, in this view, would lead to a decrease in the filtration fraction with perhaps a simultaneous increase in renal blood flow.

The inulin clearance in the same subject on various occasions is also quite constant. Subject E. B., for example, was examined 15 times in a period of a year and showed an extreme range of the average inulin clearance from 113 to $137 \mathrm{cc}$. per minute with a mean clearance of $122 \mathrm{cc}$.

The relative constancy of the inulin clearance and the phenol red/inulin clearance ratio in the present series is perhaps attributable in part to the fact that the observations have been made under standardized and fairly basal conditions: the subjects were examined in the morning without breakfast and with a minimum amount of physical activity; to produce a uniform degree of hydration, one to two liters of water are administered the day previous and two liters on the morning of examination (from $5: 30$ to $8: 30$ a.m.) the last water being taken at least 90 minutes before the first clearance period. But contributing equally to this constancy is the fact that the technique of clearance determination is designed to give the most accurate results obtainable. The use of constant, slow infusions gives reliable blood curves of inulin and phenol red, and catheterization of the bladder followed by a careful washing with saline eliminates what is perhaps the largest source of error. This last precaution is obviously necessary if single clearance determinations are to be given any physiological significance. It is at times difficult to obtain complete emptying of the bladder even when a multiple-opening catheter is used and the bladder is washed out with $20 \mathrm{cc}$. of saline.

It is appropriate to note in this connection the variability to be expected in single, successive clearance determinations. We have subjected our individual inulin clearance determinations to analysis as follows: the extreme high and low values of this clearance in each series of observa- tions (as shown by the vertical lines in Figures $7 a$ and $b$ ) have been used to calculate a standard deviation relative to the average value of all observations on that day taken as unity. The standard deviation thus calculated for 356 periods is $\pm 0.089,69.5$ per cent of the determinations falling within once, 96 per cent within twice and 100 per cent within 3 times the standard deviation. It follows that a variation of any individual clearance, from the average of a series of clearances on one day, of more than 8.9 per cent should not occur oftener than 30.5 times, and a variation of more than 17.8 per cent should not occur oftener than 4 times, in 100 determinations. Unexpected changes in renal activity do unquestionably occur in a subject on repeated examination, but in no instance are these changes of such a magnitude as to invalidate the physiological significance of the average of a series of three or four observations on any one day.

We conclude from the present data on normal subjects that renal activity, particularly as revealed by the inulin clearance, is remarkably constant under standard conditions, not only in the same subject in successive 15 to 20 minute periods, but week by week; this clearance is also relatively constant in different subjects. We believe that the highly variable clearances reported by other investigators are attributable in great part to various technical errors, and chiefly to failure to empty the bladder completely.

In considering whether or not the data in Table III furnish reliable standards for normal renal activity, attention should be called to the fact that the two individuals with low inulin clearances shown at the bottom of the table have been excluded from the calculation of the average figures. Though nothing in the history of these individuals indicates renal disease, it was felt that this could not confidently be excluded.

We have included the urea clearance in some of our observations because of the great practical importance of this determination. Contrary to the usual practice, we determine urea concentration in the plasma rather than in whole blood, a practice defensible on physiological grounds since the calculation of the fraction of urea reabsorbed by the tubules is based upon the plasma rather than the whole blood clearance. If allowance is made for the difference between plasma and 
whole blood clearance, our average figure is in agreement with the widely accepted figures of Möller, McIntosh, and Van Slyke (11).

\section{SUM MARY}

The data given in Table II are too limited in number to establish normal values, but so far as the six individuals reported there are concerned, the minimal renal plasma flow, as measured by the diodrast clearance, has an average value of 820 cc. per 1.73 sq. m. surface area per minute. This corresponds to a minimal whole blood flow of $1384 \mathrm{cc}$. Although there is little reason to believe that such is the case, these figures may be slightly elevated by a vasodilator action of diodrast and by circulatory acceleration associated with clearance determination. Of 820 cc. of plasma, an average of $137 \mathrm{cc}$. per minute are filtered, as indicated by the inulin clearance. Thus the average filtration fraction is 16.7 per cent. Applying this figure to the average inulin clearance, as given in Table III, it appears that the minimal, basal effective blood flow through the two kidneys of ideal man averages about $1300 \mathrm{cc}$. per minute.

Observations on the extent to which the tubular excretory mass and the effective renal blood flow may be altered by various physiological or pharmacological agents, or in the course of disease, are now in progress and will be reported at a subsequent time, with supplementary data on the normal value of $T_{m}$.

\section{CONCLUSIONS}

1a. Methods are described for measuring the tubular excretory mass and the effective renal blood flow in the human kidney. These methods are based on the capacity of the renal tubules to remove certain foreign substances from the blood and to excrete them into the urine, independently of the activity of the glomeruli.

$b$. Data on a limited series of subjects are given for the effective renal blood flow and the fraction of plasma filtered at the glomerulus.

2. As subsidiary matters of physiological importance in the development of these methods, it is shown

a. That phenol red, diodrast, and hippuran are excreted by a common cellular mechanism in the tubules. $b$. That tubular excretory activity is limited, in that there is a maximal rate of excretion for each substance.

c. That no significant quantity of diodrast or hippuran (or, from previous data, of phenol red) is stored in the renal tubules.

3. Values are given for the inulin and phenol red clearances in normal man. These clearances are shown to be quite constant from time to time in the same subject and in different subjects.

These investigations have required the collaboration of a number of workers, Dr. Robert W. Clarke, Dr. Catherine Welsh, Dr. Hilmert A. Ranges, Dr. Willie W. Smith, Miss Helen Keigher, Miss Anna Rosenthal and Miss Anne Rivoire. We are especially indebted to Dr. Willie W. Smith for the development and supervision of the iodine method in this laboratory and to Dr. Bernard Brodie of the Department of Pharmacology for advice concerning this method.

We are indebted to Messrs. Hynson, Wescott, and Dunning for their cooperation in preparing sterile 10 per cent phenol red solution, and to the Pfanstiehl Chemical Company for their cooperation in the preparation of inulin suitable for intravenous use in man.

\section{METHODS}

1. Preparation of infusion fluid. To establish and maintain a blood plateau in the shortest time a priming infusion (designated here as Number 1) is given at 10 cc. per minute, followed by one or more sustaining infusions of appropriate composition at the rate of $4 \mathrm{cc}$. per minute.

The preparation of inulin suitable for intravenous administration has been described elsewhere (15); impure preparations may produce severe reactions, and it is imperative that a physiologically certified preparation be used. We have recently removed the pyrogenic agent by filtering the inulin solution before use through a Seitz E.K. asbestos filter, as recommended by Co Tui et al. (3). Since inulin has a very high molecular weight $(20)$ it has negligible osmotic properties and it must be administered in saline ( 0.9 to 1.0 per cent). The solution is prepared by dissolving the inulin in sterile saline with the aid of heat and filtering while hot through a Seitz filter if the inulin is pyrogenically reactive; it is then boiled for 5 minutes in a loosely stoppered flask to effect sterilization, and sterile phenol red, hippuran, etc. are added. The infusion flask and tubing are filled with hot saline to remove air; this is then drained off to the bottom of the infusion flask, and after the inulin solution has been transferred to the flask a volume of fluid corresponding to the dead space of the infusion tubing is drained off in order to bring the inulin solution down to the needle. Inulin is only slightly soluble in cold water, and although it readily forms a supersaturated solution when heated, the solution should be transferred to the infusion flask while hot to prevent crystallization. A 10 
per cent inulin solution will usually remain at body temperature for one hour without crystallization, while a 3 per cent solution keeps several hours. It is our practice to pass the fluid through a glass coil immersed in a water bath at body temperature, since with this precaution the fluid in the infusion flask may be started at a considerably higher temperature. A T-tube carrying a thermometer is inserted in the infusion tubing between the cooling coil and the needle, to afford a check on the temperature of the infusion fluid as it enters the arm. Where it is desirable to change the infusion fluid during the course of a series of observations, this can be done quickly by withdrawing the adapter from the needle, draining the old infusion fluid to the bottom of the flask, substituting the second infusion fluid and discarding a volume of fluid equal to the dead space of the tubing. A special tunnel clamp which gives uniform compression over the infusion tubing for a distance of 4 inches is used to control the rate of infusion, which is measured by means of a graduated pipette communicating with the infusion flask by a Y-tube. The emptying time of this tube is noted with a stop watch.

Where low urine flows may result from experimental procedures, diuresis should be maintained by incorporating 2 per cent $\mathrm{Na}_{2} \mathrm{SO}_{4}$ in the infusion fluid, to prevent inulin from crystallizing out in the urine.

2. Collection of urine and blood. Urine is collected by an inlying catheter, the urine being allowed to drain into a narrow-necked flask during the collection period. Toward the close of the period air is blown into the bladder by syringe and the last of the urine removed by suction; the bladder is then washed out with an accurately measured volume of saline and a small quantity of air. The termination of the period is timed as closely as possible to the removal of the last of this wash fluid. A sterile catheter is used and sterile gloves are worn. The urine and wash fluid are combined for analysis, and a preliminary 1:10 dilution is made at once to prevent precipitation of the inulin.

Blood samples are drawn from the antecubital vein, using double strength colorless heparin (Connaught Laboratories) to prevent clotting. The blood is centrifuged at once, the plasma separated, and an accurately measured $2 \mathrm{cc}$. sample is set aside for inulin analysis. Oxalate is added to the rest of the plasma which is used for phenol red and hippuran analysis. Two cc. of plasma are required for inulin, $2 \mathrm{cc}$. for phenol red and in general $10 \mathrm{cc}$. for duplicate iodine analysis.

3. Analytical methods. Inulin analyses are carried out on copper sulphate-sodium tungstate filtrates (18), the plasma and urines being diluted $1: 8$ or $1: 10$ in precipitation, the urines first being diluted to the approximate $\mathrm{U} / \mathrm{P}$ ratio as calculated from the urine flow and probable inulin clearance. Glucose is absorbed from the filtrates of both plasma and urine by treating $5 \mathrm{cc}$. of filtrate with 1 cc. of packed yeast which has previously been well washed to remove all reducing substances. The filtrate is left in contact with the yeast for 15 minutes, with occasional stirring, before being centrifuged again.
The method of inulin analysis now in use and which has been repeatedly tested for recoveries of inulin is as follows.

Two-tenths cc. $\mathrm{N} \mathrm{H}_{2} \mathrm{SO}_{4}$, accurately measured from a capillary pipette, are carefully placed in the bottom of a Folin sugar tube. Two cc. of filtrate are introduced on top of the acid, delivering this filtrate against the constriction of the tube. The mixture is agitated slightly and the inulin is hydrolyzed by placing it in boiling water for 15 minutes. Two-tenths cc. of $\mathrm{N} \mathrm{KOH}$ are then pipetted against the constriction and a drop of phenolphthalein is added. If the mixture is alkaline a drop of $0.1 \mathrm{~N} \mathrm{H}_{2} \mathrm{SO}_{4}$ is added. When acid, 1 per cent $\mathrm{Na}_{2} \mathrm{CO}_{3}$ is added drop by drop until the mixture is a permanent pink. This should not require more than 2 drops of $\mathrm{Na}_{2} \mathrm{CO}_{3}$ and the use of a larger quantity introduces perceptible error in the glucose determination. Two cc. of the copper tartrate solution (6) are then added and the inulin is determined as fructose. The simultaneous bloods and urines are boiled together and read against a common standard. All sugars are read in a Duboscq colorimeter against a single standard containing $15 \mathrm{mgm}$. per cent of glucose which has been boiled with the unknowns. Inulin recoveries from both blood and urine have been satisfactory from 7.5 to $25 \mathrm{mgm}$. per cent in the filtrate. (It should be noted that the use of a single standard as described above does not give complete recoveries of glucose throughout so wide a range.) By this method inulin has a glucose equivalent of about 100 per cent, and all figures are reported as apparent glucose. Six bloods and fifteen urines can be analyzed in duplicate in this manner in an afternoon and morning.

Prior to phenol red analysis the oxalated plasma is centrifuged at high speed in heavy walled Pyrex tubes to remove oxalates and red cells, hemolysis of the latter introducing error. Two cc. of plasma are alkalinized with a drop of saturated $\mathrm{Na}_{2} \mathrm{CO}_{3}$ and compared with 2 cc. of a $1.0 \mathrm{mgm}$. per cent phenol red solution similarly alkalinized in a Duboscq microcolorimeter. If, on alkalinization, the plasma becomes cloudy it is necessary to centrifuge again. Reading should be done within 30 minutes. An $\in 74$ Wratten filter is placed in the eyepiece and the colorimeter is illuminated by a Photoflood bulb with a variable resistance. If it is necessary to dilute the plasma before reading in the colorimeter, saline must be used as a diluent to prevent precipitation of the globulins. Analysis of the diluted urines is carried out in a similar manner.

Where the plasma level of phenol red is kept close to $1.0 \mathrm{mgm}$. per cent, a single blank determination is made by adding $1.0 \mathrm{cc}$. of $2.5 \mathrm{mgm}$. per cent phenol red solution to $2.0 \mathrm{cc}$. of the patient's plasma drawn prior to the first infusion. This is read against a $1.0 \mathrm{mgm}$. per cent standard and the apparent blank determined by subtracting 0.83 and multiplying by 1.5 . This blank ( 0 to 0.10 mgm. per cent) is deducted from all plasma phenol red readings. Each sample of plasma is tested for hemolysis by a slight modification of Bing and Baker's (1) hemoglobin method: $2 \mathrm{cc}$. of a 2 per cent benzidine solution 
in 20 per cent glacial acetic acid are added to $0.4 \mathrm{cc}$. of plasma plus $0.6 \mathrm{cc}$. of water, the mixture agitated, and 1.0 cc. of 1.5 per cent $\mathrm{H}_{2} \mathrm{O}_{2}$ added. A blank using 1.0 cc. of water is prepared in the same manner. The solutions are grossly compared after 1 hour, and if hemolysis is present the phenol red determination is discarded.

Iodine analysis is carried out by Kendall's (9) method, with slight modifications which may be briefly noted to supplement the original description. All samples are dried at $90^{\circ}$ C. before fusion with $\mathrm{NaOH}$. Heat resistant glass beads (15 to 20 ) are used to prevent boiling over; after use these are washed, boiled with dilute $\mathrm{H}_{8} \mathrm{PO}_{4}$, washed and dried at $90^{\circ}$. Only $2 \mathrm{cc}$. of 20 per cent sodium bisulphite are used instead of $5 \mathrm{cc}$; $1.5 \mathrm{cc}$. excess of $\mathrm{H}_{8} \mathrm{PO}_{4}$ are added after the methyl red endpoint is reached, and the final addition of reduced $\mathrm{H}_{3} \mathrm{PO}$, is omitted. Sodium thiosulphate is standardized by titration of $5 \mathrm{cc}$. of $\mathrm{N} 0.001 \mathrm{KIO}_{3}$ added to a dummy prepared of $\mathrm{NaOH}, \mathrm{H}_{8} \mathrm{PO}_{4}$, etc., as in the analysis of unknowns. All reagents are carefully examined for a blank. Thirty-five analyses of $\mathrm{KIO}_{3}$ or $\mathrm{KI}$ varying from $25 \gamma$ to $100 \gamma$ added to plasma have given recovery with a S.D. of $\pm 1.44 \gamma$. Similarly, diodrast added to plasma in quantities less than $100 \gamma$ has been recovered with a S.D. $\pm 1.84 \gamma$ (20 observations). Seventy per cent of routine determinations check within 2 per cent, 93 per cent check within 5 per cent.

Ureas are determined by Van Slyke's (19) manometric urease method, using plasma and diluted urines, digestion in each case being carried out in the burette.

Plasma proteins are determined by Wu's (22) method with the addition of lithium sulphate to the phenol reagent (7).

4. Protocols. Since many of the observations recorded here involve infusion fluids of special composition the more important features of these fluids and their manipulation will be reviewed. For brevity the following abbreviations are used: phenol red, PR.; diodrast, D.; hippuran, H.; urine collection period, U.; blood sample, B. The time at the beginning of the priming infusion is indicated by 0 and the elapsed time thereafter by $10^{\prime}$, $1^{\prime}$, etc. Phenol red is used as a sterile 10 per cent solution prepared for us by Hynson, Wescott, and Dunning; diodrast is the 35 per cent sterile solution marketed by the Winthrop Chemical Co., and hippuran is the 48 per cent sterile solution marketed by the Mallinckrodt Chemical Company. $U_{1}$ begins about 20 minutes after infusion No. 2 is started.

Figure 1. Inf. No. 1: $15 \mathrm{gm}$. inulin, $1.5 \mathrm{cc}$. PR, $1 \mathrm{cc}$. D. in $100 \mathrm{cc}$. saline from 0 to $10^{\prime}$. Inf. No. 2: $50 \mathrm{gm}$. inulin, $10 \mathrm{cc}$. PR., $10 \mathrm{cc}$. D. in $1000 \mathrm{cc}$. saline at $4 \mathrm{cc}$. per min. until end. From $60^{\prime}$ to $67.5^{\prime}, 70$ cc. 10 per cent $P R$. solution injected into infusion tubing near arm. Discard period from $59^{\prime}$ to $73^{\prime}$. Total time, $200^{\prime}, 14$ urines and 7 bloods.

Figure 2. Inf. No. 1: $15 \mathrm{gm}$. inulin, $1.5 \mathrm{cc}$. PR., $1.5 \mathrm{cc}$. D. in $100 \mathrm{cc}$. saline from 0 to $1^{\prime}$. Inf. No. 2: $20 \mathrm{gm}$. inulin, 4 cc. PR., 4 cc. D. in 400 cc. saline at 4 cc. per min. from $11^{\prime}$ to $75^{\prime}$. Inf. No. $3: 25 \mathrm{gm}$. inulin, $2 \mathrm{cc}$.
PR., 25 cc. D. in 500 cc. saline from $79^{\prime}$ to end. From $84^{\prime}$ to $89^{\prime} 50 \mathrm{cc}$. D. injected into infusion tubing. Discard from 74' to $99^{\prime}$. Total time, 186', 11 urines and 6 bloods. $B_{0}$ to $B_{6}$ at $0^{\prime}, 40^{\prime}, 75^{\prime}, 98^{\prime}, 120^{\prime}, 150^{\prime}$ and $186^{\prime}$, respectively.

Figure 3. Inf. No. 1: $12 \mathrm{gm}$. inulin, 2 cc. PR., $1 \mathrm{cc}$. $\mathrm{H}$. in $100 \mathrm{cc}$. saline from 0 to $1^{\prime}$. Inf. No. 2: $20 \mathrm{gm}$. inulin, 4 cc. PR., 4 cc. $H$. in 400 cc. saline at 4 cc. per min. from $11^{\prime}$ to $71^{\prime}$. Inf. No. 3:30 gm. inulin, $2 \mathrm{cc}$. PR., 50 cc. H. in 500 cc. saline from $72^{\prime}$ to end. At $82^{\prime}$, 91.5' and 102', 24, 12 and $8 \mathrm{cc}$. H. mixed with infusion fluid in flask. Total time, 197', 11 urines and 6 bloods.

Figure 4. Inf. No. 1 : $15 \mathrm{gm}$. inulin, $1.5 \mathrm{cc}$. PR., $1 \mathrm{cc}$. D. or $H$. in $100 \mathrm{cc}$. saline from 0 to $10^{\prime}$. Inf. No. 2: 30 gm. inulin, $4.8 \mathrm{cc}$. PR., $6 \mathrm{cc}$. D. or H. in $600 \mathrm{cc}$. saline at 4 cc. per min. from $10^{\prime}$ to end. After three control urine periods, from 3 to $10 \mathrm{cc}$. of $\mathrm{D}$. or $\mathrm{H}$. were injected slowly into infusion tubing or directly in vein of other arm. Total time, about $120^{\prime}, 8$ urines and 5 bloods.

Figure 5. Inf. No. 1: $12 \mathrm{gm}$. inulin and $1.5 \mathrm{cc}$. PR. in $100 \mathrm{cc}$. saline from 0 to $10^{\prime}$. Inf. No. 2: $12 \mathrm{gm}$. inulin, 2.25 cc. PR., 300 cc. saline, 10 to $52^{\prime}$. Inf. No. 3: 16 gm. inulin, 2.0 cc. PR., 40 cc. D. in 400 cc. saline, 53.5' to $120.5^{\prime}$. At $59.5^{\prime}$ and $70^{\prime}$, respectively, 12 and $6 \mathrm{cc}$. D. added to infusion flask. Inf. No. 4: $12 \mathrm{gm}$. inulin and 2.25 cc. PR. in 300 cc. saline from $120.5^{\prime}$ to end. Discard periods from $52^{\prime}$ to $64^{\prime}$ and $118.5^{\prime}$ to $130^{\prime}$. Total time, 159', 11 urines and 7 bloods.

Figure 6. Inf. No. 1: $15 \mathrm{gm}$. inulin and $1.5 \mathrm{cc}$. PR. in $100 \mathrm{cc}$. saline from 0 to $10^{\prime}$. Inf. No. 2: $15 \mathrm{gm}$. inulin and $2.25 \mathrm{cc}$. PR. in $300 \mathrm{cc}$. saline from $10^{\prime}$ to $50^{\prime}$. Inf. No. 3: $20 \mathrm{gm}$. inulin, $1.6 \mathrm{cc}$. $P R$. and $47 \mathrm{cc}$. H. in $400 \mathrm{cc}$. saline, $52^{\prime}$ to $115.5^{\prime}$. At $57^{\prime}$ and $68^{\prime}$ respectively, 13 and $7 \mathrm{cc}$. of $\mathrm{H}$. added to infusion flask. Inf. No. 4 : $15 \mathrm{gm}$. inulin and $2.0 \mathrm{cc}$. PR. in $300 \mathrm{cc}$. saline, $115.5^{\prime}$ to end. Discard period $62^{\prime}$ to $73^{\prime}$. Total time, 157'. 13 urines and 8 bloods.

Tables $I, I I$ and $I I I$. The routine examination of normal individuals of 1.7 sq. m. S.A. may be accomplished as follows: Inf. No. 1: $15 \mathrm{gm}$. inulin, $1 \mathrm{cc}$. PR. and $1 \mathrm{cc}$. D. in $100 \mathrm{cc}$. saline from 0 to $10^{\prime}$. Inf. No. 2: $15 \mathrm{gm}$. inulin, $3 \mathrm{cc}$. PR. and $3 \mathrm{cc}$. D. in $300 \mathrm{cc}$. saline, $10^{\prime}$ to end at $4 \mathrm{cc}$. per minute. These infusions will give 100 to $150 \mathrm{mgm}$. per cent of inulin, 0.75 to $1.0 \mathrm{mgm}$. per cent of PR. and 0.5 to $1.0 \mathrm{mgm}$. per cent of $\mathrm{D}$. in the plasma, depending on clearances. $B_{0}$ for $P R$. blank may be drawn when starting inf. No. $1, B_{1}$ at $28^{\prime}, B_{2}$ at $60^{\prime}$ and $\mathrm{B}_{3}$ at $92^{\prime}$, and the bladder emptied and washed at $30^{\prime}$, with $U_{1}$ at $45^{\prime}, U_{2}$ at $60^{\prime}, U_{8}$ at $75^{\prime}$ and $U_{4}$ at $90^{\prime}$. It was by essentially this technique that most of the data in Table III were collected, though a few of the earlier observations were made on falling blood curves after single intravenous injections. Where the clearance of any substance is reduced, the concentrations in the infusion fluid should be reduced approximately in proportion to the square root of the per cent of normal clearance, keeping the infusion rate at $4 \mathrm{cc}$. per minute.

Protocol 2 may be followed for measuring both maximal clearances and $T_{m}$. 


\section{BIBLIOGRAPHY}

1. Bing, F. C., and Baker, R. W., The determination of hemoglobin in minute amounts of blood by Wu's method. J. Biol. Chem., 1931, 92, 589.

2. Chambers, R., and Kempton, R. T., Indications of function of the chick mesonephros in tissue culture with phenol red. J. Cell. and Comp. Physiol., 1933, 3, 131.

3. Co Tui, McCloskey, K. L., Schrift, M., and Yates, A. L., A new method of preparing infusion fluids based on removal of pyrogen by filtration. J. A. M. A., 1937, 109, 250.

4. Elsom, K. A., Bott, P. A., and Shiels, E. H., On the excretion of skiodan, diodrast and hippuran by the dog. Am. J. Physiol., 1936, 115, 548.

5. Elsom, K. A., Bott, P. A., and Walker, A. M., The simultaneous measurement of renal blood flow and the excretion of hippuran and phenol red by the kidney. Am. J. Physiol., 1937, 118, 739.

6. Folin, O., Two revised copper methods for blood sugar determination. J. Biol. Chem., 1929, 82, 83.

7. Folin, O., and Ciocalteu, V., On tyrosine and tryptophane determinations in proteins. J. Biol. Chem., 1927, 73, 627.

8. Goldring, W., Clarke, R. W., and Smith, H. W., The phenol red clearance in normal man. J. Clin. Invest., 1936, 15, 221.

9. Kendall, E. C., Determination of iodine in connection with studies in thyroid activity. Third paper. J. Biol. Chem., 1920, 43, 149.

10. Landis, E. M., Elsom, K. A., Bott, P. A., and Shiels, E. H., Simultaneous plasma clearances of creatinine and certain organic compounds of iodine in relation to human kidney function. J. Clin. Invest., 1936, 15, 397.

11. Möller, E., McIntosh, J. F., and Van Slyke, D. D.,
Studies of urea excretion. II. Relationship between urine volume and the rate of urea excretion by normal adults. J. Clin. Invest., 1928, 6, 427.

12. Shannon, J. A., The kinetics of tubular excretion. (In preparation.)

13. Shannon, J. A., and Smith, H. W., The excretion of inulin, xylose and urea by normal and phlorizinized man. J. Clin. Invest., 1935, 14, 393.

14. Smith, H. W., The Physiology of the Kidney. Oxford University Press, New York, 1937.

15. Smith, H. W., Chasis, H., and Ranges, H. A., The suitability of inulin for intravenous administration. Proc. Soc. Exper. Biol. and Med., 1938, 37, 726.

16. Smith, H. W., Goldring, W., and Chasis, H., The renal extraction ratio of urea, phenol red and diodrast in man. (In preparation.)

17. Smith, W. W., and Smith, H. W., Protein binding of phenol red, diodrast and other compounds in plasma. J. Biol. Chem., 1938, 124 (In press).

18. Somogyi, M., The use of copper and iron salts for the deproteinization of blood. J. Biol. Chem., 1931, 90, 725.

19. Van Slyke, D. D., Determination of urea by gasometric measurement of the carbon dioxide formed by the action of urease. J. Biol. Chem., 1927, 73, 695.

20. Westfall, B. B., and Landis, E. M., The molecular weight of inulin. J. Biol. Chem., 1936, 116, 727.

21. Winkler, A. W., and Parra, J., The measurement of glomerular filtration. Creatinine, sucrose and urea clearances in subjects without renal disease. J. Clin. Invest., 1937, 16, 859.

22. Wu, H., A new colorimetric method for the determination of plasma proteins. J. Biol. Chem., 1922, 51, 33. 